\title{
Modern Marketing Tools in the Condition of Globalization
}

\author{
Olga Ponisciakova ${ }^{1, *}$, Eva Kicova ${ }^{2}$ \\ ${ }^{1}$ University of Zilina, Faculty of Operation and Economics of Transport and Communications, \\ Department of Economics, 010 26, Univerzitna 26, Zilina, Slovakia \\ ${ }^{2}$ University of Zilina, Faculty of Operation and Economics of Transport and Communications, \\ Department of Economics, 010 26, Univerzitna 26, Zilina, Slovakia
}

\begin{abstract}
.
Research background: CRM is one of the most popular tools of modern marketing in today's globalized world. It is a purposefully set up management with customers, which synchronizes several internal company processes. Its justification is indisputable, as it is generally the case that companies that do not engage in customer relationship management are soon overshadowed by competition and fall into extinction. With the help of CRM, the company can manage not only the sale of products to customers but also following service. Sales staff, call center staff, service department staff and many others can thus use the CRM system. The subject of research in the paper is the use of CRM in Internet commerce.

Purpose of the article: The development of a functional CRM system in a specific company and the introduction of selected CRM tools in the company's online store can be considered a priority goal.

Methods: During the elaboration of the paper, the methods of the compilation of analysis, synthesis and description were used on the basis of the search of the relevant literature.

Findings \& Value added: The paper contains findings on two levels. From the theoretical point of view, it provides an overview of the essence, development, individual elements, customer relationship strategy, as well as the technical architecture and possibilities of CRM implementation. From the practical point of view, it is about the design of a functional CRM system in a specific company and the introduction of selected CRM tools in the company's online store In contrast, the CRM application in specific business conditions represents added value.
\end{abstract}

Keywords: CRM; management; globalization; customer relations; customer value

JEL Classification: $M 3$

* Corresponding author: olga.ponisciakova@fpedas.uniza.sk 


\section{Introduction}

The topic of globalization and its effects on the lives of individuals or society is still relevant. It affects a person's life in the field of work as well as in private, and the effects are not only positive but also negative. In the business environment, the fact is that due to the impact of international trade, with increasing competitive power, the expansion of technology and innovation, as well as the application of scientific and technological progress in production and overall globalization, every entrepreneur, resp. the company make every effort to gain customers. Every company must realize that gaining a customer is not enough, it is necessary to develop a level of customer relationship management. A progressive approach to improving management also leads to improving the development of managers themselves. According to Chlebikova et all [1], personal development planning should ensure the motivation of employees in the company and should enable employees to develop their professional skills, provide them with a certain job perspective and increase the attractiveness of work in the company. A company that can satisfy the needs of customers to their satisfaction can build a stable relationship with customers and also gain customer loyalty. This is also supported by Batista et all [2], who argue that successful organizations are characterized by how they adapt their organizational practices in response to the external environment. Successful organizations are characterized by how they adjust their organizational practices in response to the external environment.

From the point of view of history, it can be stated that the beginnings of CRM date back to the times of the creation of the first files, accounting books, etc. However, in these times, interest in customers was minimal. Therefore, it is necessary to take a look at the $80 \mathrm{~s}$ of the 20th centuries, when the first systems for recording and processing customer data began to appear. The invention of the 20th century - the Internet - is clearly behind the possibility of creating a CRM system. The definitive selection and adoption of the CRM label took place in 1995. Customer relationship management is therefore not a new concept. However, its form, material or formal, is evolving. Currently, the proof of this statement is the application of the so-called S-CRM, which is researched in terms of practical application compared to traditional CRM. As Harrigan et al. [3] point out, their research reveals findings that S-CRM differs from traditional CRM in different ways in front and back offices and provides a framework for information systems and marketing researchers and managers to operate at a strategic and tactical level within S-CRM, while being reciprocal. Findings show that S-CRM is different from traditional CRM in a range of ways in the front- and back-offices, and provide a framework for researcher and managers in information systems and marketing to operate at strategic and tactical levels within S-CRM, while being cognizant of both. Similarly, Rodriguez, M., Boyer, S., [4] assessed that research overall empirically demonstrates that mCRM plays an important role in traditional CRM adoption and sales performance, involving sales capabilities and collaboration. Overall, the research empirically demonstrates that mCRM plays an important role in traditional CRM adoption and in sales performance when sales process capabilities and collaboration are involved. Last but not least, as Krizanova et al. [5] argues, based on the data acquisition methodology, we can evaluate the level of CRM and the performance measurement model not only as an indicator of the current situation, but also as a forecast with a retrospective view, because companies that they decide to obtain information from customers, they will want to approach the required optimal value of customers.

Internet technologies produce new marketing tools and tactics that help companies attract and retain customers [6].

The current number of multinational companies is constantly striving to come up with new approaches in this area of management. However, it should be noted that there are also those that underestimate this area of customer relationship management. 


\subsection{CRM formation}

In order to clarify the concept of CRM (customer relationship management), a professional context is also necessary. Like every concept, the concept of CRM had its predecessors and history until it was formed into its current form. Zavoral [7] thoroughly described all the forms and systems that were the predecessors of CRM, and then moved on to the period when and under what conditions the concept of CRM was coined. Rolinek [8] described how the development of the Internet from Arpanet took place, the original intention of which was not to be used for commercial purposes, but thanks to later use for commercial purposes, a breakthrough and the creation of a CRM system could occur in the near future; Chlebovsky [9] divides the developmental stages according to the sequence:

1. paper database system,

2. a solution based on an Office suite,

3. programs for contact management and time management,

4. Comprehensive CRM E-Systems.

In most publications and articles for the 35-year existence of the term CRM, it is possible to meet the explanation of CRM in a fairly identical form, in a smaller number of publications the authors try not only to supplement but also a completely new view of the term CRM. The authors Storback K. and Lehtinen J. R [10] divided the relationship with the customer into three phases: establishing, developing and ending the relationship. However, Hana Lostakova et al. [11], have such an opinion that the relationship with the customer should be defined separately in the phases of finding a relationship and relationship stability [12]. Abdullateef A. O. \& Salleh S. M. [13] argue that call centers represent an extension of their traditional CRM tools. Many authors agree that the quality of call centers also improves the quality of CRM and the overall satisfaction of customer needs. Cerchia Alina Elena [14] clarified the current influence of social media on CRM, i.e. the transition of traditional CRM to the new concept of SCRM (Social Customer relationship management). Munyaradzi W. Nyadzayo and Saman Khajehzade [15] point out how necessary it is to establish a relationship with customers and subsequently gain their loyalty. According to the authors, the quality of CRM consists of the quality of services, satisfaction of customer needs and customer value. Subsequently, the quality of CRM results in customer loyalty. Ramendra Thakur and Letty Workman [16] proposed a view of the customer by the company from two perspectives, namely the price of services spent on customers and the value for the company that flows from customers and were able to divide customers into four groups: bronze customer, silver customer, gold customer and platinum customer. Ameed Pandit, Sonia Vilches-Montero [17], draws attention to the fact that reward cards can be attractive to customers as a form of reward from retailers (businesses). In this way, companies can try to establish a long-term relationship with customers. In this study, they sought to examine when and how a reward card, how a CRM tool can evoke long-term commitment and customer loyalty to a business. According to the article, customers who use the reward card for a longer period of time tend to have more trust and overall satisfaction with the company. According to Vachal [18], there has been talk of a globalized market economy since 1996. Manifestations of globalization that are easiest to recognize and that are important for customer relationship management are, for example: local hypercompetition in various markets (supply exceeds demand), the existence of multinational companies that come up with new approaches to management. Therefore, a new idea was created in CRM: value management for the addressed market in the mode of sustainable economic and ecological development of the planet. Companies approach the idea of value management (VM) and the trend of global quality value 
management (GQVM) and the ideas of older theory and practice TQM (Total Quality Management).

\subsection{CRM formation}

CRM functions can be derived thanks to the current understanding of CRM. It is perceived as a complex system, consisting of extensive electronic systems, including four basic CRM modules:

1. automation of sales activities - Sales Force Automation (SFA),

2. automation of marketing activities - Marketing Automation (MA),

3. automation of service activities and customer support - Field Service Automation (FSA), call center automation - Call Center (CC),

4. Electronic commerce - E-business (EB) (Chlebovsky, 2002).

Automation of sales activities is perceived as a cornerstone of CRM. The module should allow all traders or external trading partners to quickly and efficiently access important customer information, work program planning and the use of knowledge bases and other sales tools included in the system. Important functions of the module include contact management and time scheduler (Contact and Time Management), management of new, as yet unidentified contacts (Lead Management), including distribution of new contacts to responsible salespeople and monitoring and feedback of further communication with potential clients, creation tools Management Reporting Tools, which allow managers to maintain a constant overview of customers in a condensed and efficient form, tools for remote access to systems, providing fast and efficient access to the system outside the office and, last but not least, management of business partners, ensuring effective cooperation with distributors and other business partners working with company products.

Automation of marketing activities is an essential activity of the company, which is key to long-term and successful customer care and strategy creation. Creating company strategies is also, like successful customer care, a long-term activity. The module performs several important functions, but the main function of the module is the management of marketing campaigns (Campaign Marketing). Management of marketing activities includes classification of customers in the database into groups, according to a certain common feature and management of separate, customized campaigns for individual groups, all available forms of communication with the customer, campaign evaluation, which is a standard part of the module, interconnection of marketing and sales module, more precisely marketing campaigns with sales teams (internal and external). Automation of service activities and customer support streamlines communication with the customer as well as management of after-sales service activities. The main functions of this module are the customer center (Customer Center) - communication with customers can take place in person, by phone or via the Internet, service center (Field Service) - is used to manage and administer service activities after sales, effective use of service technicians, spare parts and more. material according to customer needs. Businesses declare that the interest in customers on the part of the business does not end with the sale of goods or services. The last module represents electronic commerce. This is the youngest module experiencing a strong boom. In most cases, it is a standalone application (often from another vendor) based on an Internet browser access basis. It enables automated execution of a trade in electronic form. It is important to ensure maximum connectivity with other modules of the CRM system [9]. 


\section{CRM in internet commerce}

The application of CRM system tools is a very extensive issue, so we focused on technologies using various modules. On the model example of Alfa, s.r.o. we currently assume two functional online stores that use the PrestaShop system for their operation, supplemented by various modules. The PrestaShop system is freely available free of charge, but the company had to acquire and purchase a number of modules to make the system work as expected by management. At present, the company's system has 86 modules available, 13 of which had to be purchased. Due to major system modifications, it was necessary to turn off 38 modules. These modules have not been uninstalled, meaning that they can be reused by the company as needed. The remaining 48 modules are active. The PrestaShop system uses the company's MySQL database server to draw data. The database server was also used to build the company's CRM system. The client / server architecture is three-tiered.

The first layer of CRM in the company is the MySQL database server. The server is very important for storing data in a database. The database consists of extensive tables. The company has approximately 390 main tables, which are made up of additional tables. This means that the tables are logically linked to each other. Each table has a unique label and is full of different data. The data in the tables are expressed in numbers, by dates, verbally or by a combination of words and numbers (Tab. 1).

Table 1. MySQL database server.

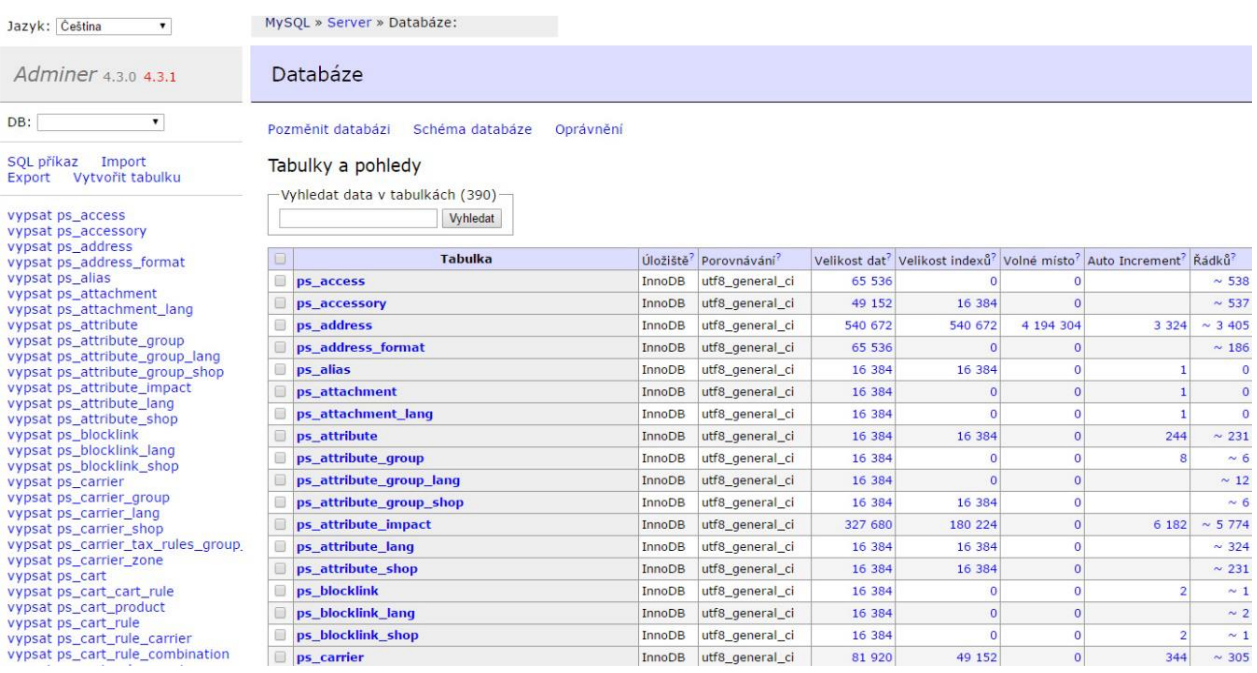

One of the tables is the so-called ps_orders table that stores all data about all company orders. Each order contains data that is divided into up to 45 columns. Each column has a different label on the basis of which the data are recorded. Column labels: order identifier (serial number), order code, customer identifier, shopping cart identifier, delivery address identifier, billing address identifier, country identifier, security code, order payment method, total order amount, VAT, order creation date, delivery date orders, total discount value and more. The data is used regularly by the company, especially for important decisions.

The second layer of CRM in the company consists of the application part, which uses distribution channels and technologies to ensure communication between the customer and the company. Communication channels between the customer and the company that 
predominate in the company include personal contact, written correspondence, electronic mail, fax communication, telephone contact and communication via the Internet. Personal contact with the customer in the store of the company - is not carried out, as the company does not have its own store.

\section{CRM system of a model company from the point of view of basic CRM modules}

CRM system in Alfa, s.r.o. can be evaluated from the point of view of CRM as a complex system. It includes electronic systems, consisting mainly of 4 basic CRM modules. When evaluating technologies, it can be stated that suppliers are neglected in this context. There is a certain systemic problem in terms of effective cooperation with them. It consists in changes in the availability of product quantities at suppliers. If e.g. a certain product is sold out it may happen that the company finds out in a few days and the only way is a manual check by the company's employees. As the product portfolio consists of 2,300 products, it is not possible to manually inspect each product by employees. The solution to the problem could be a tool that could systematically link the company's database with the supplier's inventory database. In relation to the automation of service activities and customer support, it is necessary to mention that the company has an optimized customer and service center in various ways, especially with the help of the PrestaShop system. All activities, as well as activities performed after the sale are thoroughly recorded in the company's system. This reduces the error rate in performing these activities.

The company uses a MySQL database server, which fulfills its purpose and, in particular, does not show any errors. The quality of this database server is also confirmed by the fact that it enabled the company to build a CRM system with it. The second layer is formed by the application part formed by three other parts. In the first communication part, the company does not have the opportunity to have personal contact with customers. This problem can be solved by the company's establishment plan project in order to facilitate the company's decision to establish the operation in the future. Personal contact with customers in the company's stone business could be a powerful CRM tool. In the operational part of the second layer, it is also necessary to focus on eliminating a significant shortcoming almost zero paid form of advertising. The company thus loses the possibility of a greater number of establishing relationships. It currently uses only one type of paid advertising in cooperation with Heureka Shopping s.r.o. It is necessary to incur the cost of running multiple marketing campaigns to gain new customers. The company can also use cooperation with portals that offer discounts to customers. Furthermore, it is possible to use the cooperation with the company BALÍK PLUS s. r. o., which provides a tool for targeted and effective delivery of advertising attachments to Slovak and Czech online buyers. Advertising attachments are inserted into packages of important Czech and Slovak online stores. In the analytical part, the company mainly uses the Google Analytics tool, but the tool is inaccurate when evaluating sales performance. The company will obtain more accurate analytical and statistical information by using the tools of the PrestaShop system. Therefore, it is beneficial to use these tools and possibly purchase the necessary additional modules. Through this step, the company can further effectively develop its level of customer relationship management and possibly gain an advantage over the competition. The ideal use of the CRM system is also possible by continuously updating the PrestaShop system.

The use of the CRM system in Slovakia is not new and the interest of managers in this system is increasing. The proof is also a survey conducted in selected medium and small enterprises from various areas of the national economy in the Žilina region. The survey focused mainly on inquiries about the use of CRM, which more than half of respondents 
answered in the affirmative - $61 \%$. Managers have confirmed that they use CRM systems at various levels of system capabilities. The growing trend in the interest in the use of modules is also evidenced by the efforts of companies to implement a CRM system in their business practice - in this context, $15 \%$ of respondents answered in the affirmative. $9 \%$ of respondents decide on the implementation and $15 \%$ of managers get acquainted with the issue of CRM in more detail in an effort to make the right decision when implementing CRM in their practice.

\section{Conclusion}

Creating long-term relationships with customers brings profit in the form of loyal, loyal and satisfied customers. Such customers are a rare asset and a guarantee of stability for the company and its operations. Success occurs when a customer feels a relationship not only with a particular product, with an entire company or brand.

If the customer is satisfied, he becomes loyal. He shows his satisfaction by recommending products to his close surroundings, family, friends. A big bonus for a company is obtaining information, which it often provides on its own initiative, but also a much lower sensitivity to price changes or competitive advertising.

It therefore makes sense to invest in systems that provide customer care. However, it is also important to use them as effectively as possible. Managers must therefore be constantly educated, as developing new ones or updating originals is a never-ending process.

\section{References}

1. Chlebikova, D., Misankova, M., Kramarova, K. (2015). Planning of personal development and succession. Procedia Economics and Finance, 26, pp. 249-253.

2. Batista, L., Dibb, S., Meadows, M., Hinton, M., Analogbei, M. (2020). A CRM-based pathway to improving organisational responsiveness: an empirical study. Journal of strategic marketing. 28(6), 494-521.

3. Harrigan, P., Miles, MP., Fang, YL., Roy, SK. (2020). The role of social media in the engagement and information processes of social CRM. International journal of imformation management. 54, 102151

4. Rodriguez, M., Boyer, S., (2020). The impact of mobile customer relationship management (mCRM) on sales collaboration and sales performance. Journal of marketing analytics. 8(3), 137-148.

5. Krizanova, A., Gajanova, L., Nadanyiova, M. (2019). Design of a CRM level and performance measurement model. Sustainability. 10(7), 2567.

6. Wang, S., Cavusoglu, H., Deng, ZL. (2016). Early mover advantage in e-commerce platforms with low entry barriers: The role of customer relationship management capabilities. Information and management. 53(2), pp 197-206.

7. Zavoral, P. (2015). Strucna historie CRM. http://www.itbiz.cz/clanky/strucna-historiecrm

8. Rolinek, L. a kol. (2008). Procesni management-vybrane aspekty. Ceske Budejovice: Ekonomicka fakulta Jihoceske Univerzity. 160.

9. Chlebovsky, V. (2002). CRM: Od sanonu, pastelek a diare $k$ sofistikovanemu esystemu. IT SYSTEM. https://www.systemonline.cz/clanky/crm-od-sanonu-pastelek-adiare-k-sofistikovanemu-e-systemu.htm. 
10. Storbacka, K., Lehtinen, J. R. (2002). Rizeni vztahu se zakazniky: (customer relationship management). Praha: Grada. 167.

11. Lostakova, H. (2006). Strategie diferencovaneho CRM podle hodnoty zakazniku pro podnik. Pardubice: Univerzita Pardubice. 96.

12. Kracklauer, A. H., Mills, D. Q., Seifert, D. (2012). Collaborative Customer Relationship Managment: Taking CRM to the Next Level. Berlin: Springer Science \& Business Media. 25-45.

13. Abdullateef, A. O., \& Salleh, S. M. (2013). Does customer relationship management influence call centre quality performance? An empirical industry analysis. Total Quality Management \& Business Excellence, 24(9-10), 1035-1045.

14. Cerchia, A. E. (2016). Social media - a Strategy in Developing Customer Relationship Management. Procedia Economics and Finance. 39, 785-790

15. Nyadzayo, M. W., Khajehzadeh, S. (2016). The antecedents of customer loyalty: A moderated mediation model of customer relationship management quality and brand image. Journal of retailing and consumer services. 30, 262-270.

16. Thakur, R., \& Workman, L. (2016). Customer portfolio management (CPM) for improved customer relationship management (CRM): Are your customers platinum, gold, silver, or bronze?. Journal of Business Research, 69(10), 4095-4102.

17. Pandit, A., Vilches-Montero, S. (2016). Are reward cards just a business deal?the role of calculative versus emotional card commitment in driving store loyalty. Journal of retailing and consumer services. 31, 355-360.

18. Vachal, J., Vochozka, M., Dolezalova, H., Drabkova, Z., Faltová Leitmanova, I., Hron, J., ... \& Macak, T. (2013). Podnikove rizeni. Grada Publishing. 